\title{
Cytosolic Hsp90a and its mitochondrial isoform Trap1 are differentially required in a breast cancer model
}

\author{
Evangelia Vartholomaiou ${ }^{1, *}$, Marta Madon-Simon ${ }^{1, *}$, Stéphane Hagmann ${ }^{1}$, \\ Guillaume Mühlebach ${ }^{1}$, Wolfgang Wurst ${ }^{2,3,4,5}$, Thomas Floss ${ }^{2}$ and Didier Picard ${ }^{1}$ \\ ${ }^{1}$ Département de Biologie Cellulaire, Université de Genève, Sciences III, Genève, Switzerland \\ ${ }^{2}$ Helmholtz Zentrum München, Deutsches Forschungszentrum für Gesundheit und Umwelt, Neuherberg, Germany \\ ${ }^{3}$ Deutsches Zentrum für Neurodegenerative Erkrankungen e. V., München, Germany \\ 4 Munich Cluster for Systems Neurology, München, Germany \\ ${ }^{5}$ Technische Universität München-Weihenstephan, Neuherberg, Germany \\ * These authors have contributed equally to this work
}

Correspondence to: Didier Picard, email: didier.picard@unige.ch

Keywords: Hsp90; Trap 1; breast cancer; metastasis; mouse model

Received: January 12, $2017 \quad$ Accepted: February 15, 2017

Published: February 23, 2017

\section{ABSTRACT}

The Hsp90 family of molecular chaperones includes the cytosolic isoforms Hsp90a and Hsp90 $\beta$, and the mitochondrial isoform Trap1. Hsp90a/ $\beta$ support a large number of client proteins in the cytoplasm and the nucleus whereas Trap1 regulates oxidative phosphorylation in mitochondria. Many of the associated proteins and cellular processes are relevant to cancer, and there is ample pharmacological and genetic evidence to support the idea that $\mathrm{Hsp} 90 \mathrm{a} / \beta$ and Trap1 are required for tumorigenesis. However, a direct and comparative genetic test in a mouse cancer model has not been done. Here we report the effects of deleting the Hsp90a or Trap1 genes in a mouse model of breast cancer. Neither Hsp90a nor Trap1 are absolutely required for mammary tumor initiation, growth and metastasis induced by the polyoma middle T-antigen as oncogene. However, they do modulate growth and lung metastasis in vivo and cell proliferation, migration and invasion of isolated primary carcinoma cells in vitro. Without Hsp90a, tumor burden and metastasis are reduced, correlating with impaired proliferation, migration and invasion of cells in culture. Without Trap1, the appearance of tumors is initially delayed, and isolated cells are affected similarly to those without Hsp90a. Analysis of expression data of human breast cancers supports the conclusion that this is a valid mouse model highlighting the importance of these molecular chaperones.

\section{INTRODUCTION}

Members of the Heat shock protein 90 (Hsp90) family of molecular chaperones are highly conserved, ubiquitous and abundant ATP-dependent proteins with different isoforms that share a high degree of sequence identity and can be found in several cellular compartments: Hsp90 $\alpha$ and Hsp90 $\beta$ in the cytoplasm and the nucleus, here referred to generically as Hsp90, Trap 1 in mitochondria, Grp94 in the endoplasmic reticulum, and Hsp90C in chloroplasts [1]. The cytosolic Hsp90 is a key component of an ensemble of complexes with a variety of co-chaperones [2], which acts on a wide range of protein substrates called clients (for a comprehensive overview, see https://www.picard.ch/downloads/Hsp90interactors. pdf and ref. 3).

It has been demonstrated that cytosolic Hsp90 is overexpressed in several types of cancers [3]. Moreover, Hsp90 was found to interact with a number of proteins important for breast cancer, for example the hypoxia inducible factor HIF-1 $\alpha$, estrogen receptor $\alpha$, anti-apoptotic kinase Akt, tumor suppressor protein p53, and the ErbB receptor tyrosine kinase (see https://www.picard.ch/ downloads/Hsp90facts.pdf for a comprehensive overview and references). The Hsp90 chaperone machinery can be important for tumorigenic transformation due to its 
ability to stabilize overexpressed or mutated oncoproteins or transformation-relevant signaling pathways, thereby contributing to oncogene addiction and survival of cancer cells [4-6]. Hsp90 $\alpha$ has been proposed to promote the motility, invasiveness and acquisition of stress resistance of cancer cells [7-9]. Importantly, some studies have shown that the overexpression of Hsp90 $\beta$ in breast cancer, as part of a set of proteins involved in regulating estrogen receptor $\alpha$ activity, correlates with adverse clinical outcomes [10]; a variety of Hsp90 inhibitors are in clinical trials for breast cancer treatment [11], further highlighting the potential of Hsp90 as a therapeutic target.

In addition to the intracellular pool of Hsp90, the discovery of extracellular Hsp90 $\alpha$ (eHsp90 $\alpha$ ) secreted by several normal and tumor cell lines has made the understanding of Hsp90 $\alpha$ biology even more challenging $[7,12]$. eHsp90 $\alpha$ has been proposed to be important in a number of physiological and pathophysiological processes including tumor growth [13], invasion and metastasis [7, 14], wound healing [15], and angiogenesis [16]. It has been suggested that Hsp90 secretion in normal cells only occurs under stress, but is constitutive in certain tumor cells [17], although not in all [18]. Thus, the selective sensitivity of tumor cells to Hsp90 inhibitors could be due to the inhibition of eHsp90 rather than or in addition to that of intracellular Hsp90 [17]. Since migration, invasion and metastasis are not necessarily dependent on eHsp90 in all types of cancer cells, it was speculated that sensitivity to Hsp90 inhibitors may be restricted to a subgroup of eHsp90-dependent cells [12, 17]

Initial evidence for the functions of the mitochondrial Hsp90 isoform Trap1 [19] indicated a significant protective role of this molecular chaperone against oxidative stress and cell death [20]. More recent studies have highlighted the importance of Trap1 in mitochondrial physiology and notably in the regulation of the balance between mitochondrial respiration and aerobic glycolysis [21]. However, there are contradictory conclusions among different studies as to whether Trap1 inhibits or stimulates mitochondrial respiration, indicating a complex and maybe contextual role. Since tumors rewire their metabolism towards the glycolytic pathway, even in the presence of oxygen, a phenomenon referred to as the Warburg effect [22], changes in Trap1 protein levels might facilitate this metabolic switch [21, 23]. Alterations of Trap1 expression have been reported in different types of cancer. It is overexpressed in human ovarian carcinomas resistant to platinum drugs [24], in multi-drug resistant human colorectal carcinomas [25], and in prostate [26, 27], pancreatic and lung cancers [27]. In contrast, in renal cell carcinoma, bladder and cervical cancers, Trap1 protein levels are lower when compared to normal tissue and they display an inverse correlation with tumor stage [23]. Additionally, in ovarian cancer lower levels of Trap1 were associated with more advanced disease [28]. For breast cancer, increased expression of Trap1 has been reported [27, 29]. Using a breast cancer xenograft model, a recent study showed decreased tumorigenesis when Trap1 expression was knocked down, whereas overexpression of Trap1 resulted in decreased metastasis [29].

Due to the paucity of genuine in vivo studies on the roles of Hsp90 $\alpha$ and Trap 1 in breast cancer and given the complexity of the above-mentioned observations, we decided to investigate the role of these two Hsp90 isoforms for breast cancer initiation, progression and metastasis genetically in a mouse model. Genetically engineered mouse cancer models possess several advantages over xenograft models: immunocompetent mice can be used, authentic tumor-stroma interactions are maintained, and the process of metastasis from the primary tumor may be recapitulated [30, 31]. For these reasons, we took advantage of a mouse strain carrying the oncogene polyoma virus middle T-antigen (PyMT) under the control of the mouse mammary tumor virus long terminal repeat [32]. The expression of the PyMT transgene results in the rapid development of breast adenocarcinomas with a high incidence of pulmonary metastasis [32], and it has been shown to be an adequate model to mimic human invasive ductal carcinoma [33]. Given that Hsp90-null [34] and Trap1-null [35, 36] mice are viable, we decided to investigate the importance of Hsp90 $\alpha$ and Trap1 for mammary tumorigenesis by introducing the PyMT oncogene into Hsp90 $\alpha$ - and Trap1-null mice. These genetic experiments in the mouse unambiguously address the importance of these molecular chaperones, at least for this particular model of breast cancer, and allow us to speculate about their relevance to human breast cancer.

\section{RESULTS}

\section{Expression of Hsp90 $\alpha$ and Trap1 in breast tumors and metastatic nodules}

To obtain initial correlative evidence for the potential role of Hsp $90 \alpha$ and Trap 1 in the tumorigenic and metastatic processes in the PyMT breast cancer model, we checked their protein levels in normal and cancer tissues. Hsp90 $\alpha$ levels are significantly increased in tumors compared to normal mammary gland tissue (Figure 1A and 1B), whereas Trap1 expression levels do not significantly change (Figure $1 \mathrm{~A}$ and $\mathrm{C}$ ). Our next question was whether there was any change in the protein levels of Hsp90 $\alpha$ and Trap1 in metastases compared to the primary tumors and to normal lung (Figure 1D and Supplementary Figure 1A and B). We observed a slight but not statistically significant increase in Hsp90 $\alpha$ levels in metastases compared to primary tumors (Figure 1E) and no change in Trap1 levels (Figure 1F). Significantly higher protein levels of both Hsp90 $\alpha$ (Supplementary Figure 1C) and Trap1 (Supplementary Figure 1D) were 
noted in metastatic nodules when compared to normal adjacent lung tissue. Thus, the presence of Hsp90 $\alpha$ and Trap1 through all stages of tumorigenesis is compatible with their involvement in these processes.

\section{Effects of deleting the Hsp90 $\alpha$ and Trap1 genes on tumor initiation and progression}

Hsp90a is encoded by the gene Hsp90aal; for clarity, we will refer to it here as Hsp90a. To study the effects of its deletion on mammary tumorigenesis, we compared mammary tumor initiation and progression in mice with the PyMT transgene on the two genetic backgrounds ( $H s p 90 \alpha^{+/+}$versus $\left.h s p 90 \alpha^{-/-}\right)$. The first palpable tumor was observed in both groups at a similar age (Figure 2A). We did not observe any significant differences in the overall survival of the two groups (Figure 2B). Interestingly, hsp $90 \alpha^{-/}$mice on average displayed a reduced tumor burden (Figure 2C), but not tumor number (Figure 2D), at sacrifice. The morphology of the tumors was similar in both groups as shown by hematoxylin and eosin (H\&E) staining (Figure 2E). This suggests that, in the absence of Hsp90 $\alpha$, there is a defect in tumor growth, but not in tumor initiation.
To examine the effects of the absence of Trap1 on mammary tumorigenesis, we assessed the same parameters by comparing $\operatorname{Trap}^{+/+}$with trap $^{-/}$mice. Interestingly, trap $1^{-/}$mice developed the first palpable tumors on average 3 weeks later than their wild-type littermates (Figure 2F); this is also reflected in a prolonged overall survival of the trap $1^{-/-}$mice (Figure 2G). However, at sacrifice, tumor burden (Figure $2 \mathrm{H}$ ) and number (Figure 2I) displayed no differences regardless of the presence or absence of Trap1. The tumor histopathology appeared similar in the two groups (Figure 2J). These observations indicate that loss of Trap1 results in an initial delay in the appearance of the primary tumor, but not in the subsequent tumor growth.

\section{Absence of Hsp90a, but not of Trap1, impairs the formation of lung metastases}

In the PyMT mammary cancer model, lung metastases are observed with high incidence shortly after the appearance of primary tumors [33, 37]. $82 \%$ of the wild-type $H s p 90 \alpha^{+/+}$control mice, $60 \%$ of the $h s p 90 \alpha^{-/-}$mice (Supplementary Figure 2A), and all the mice of both Trap1 groups developed lung metastases
A

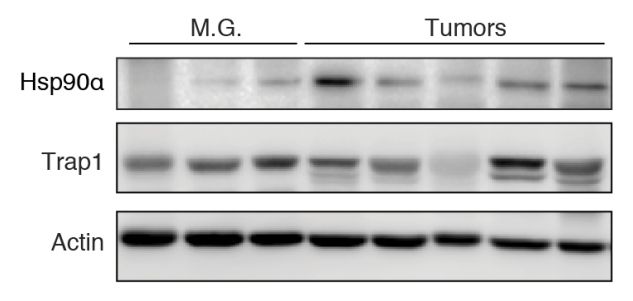

D

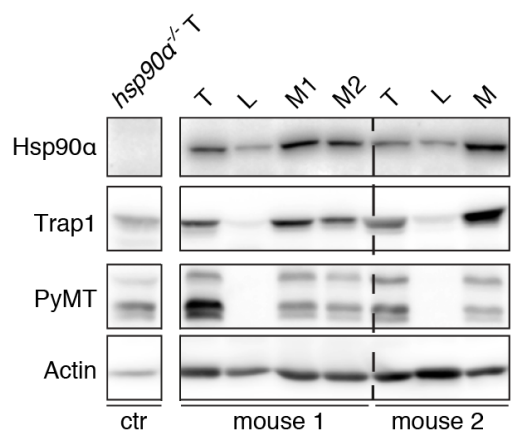

B

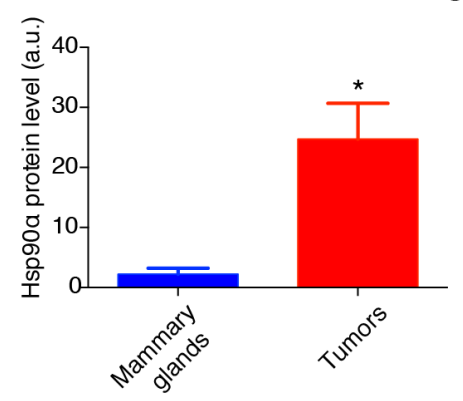

E

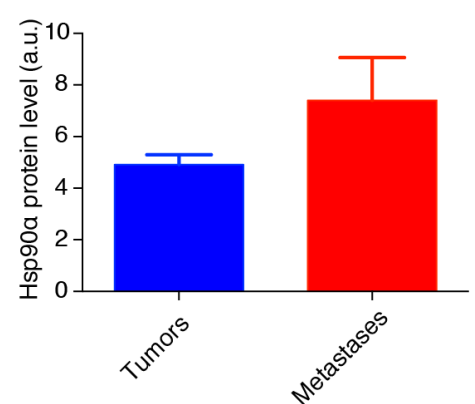

C

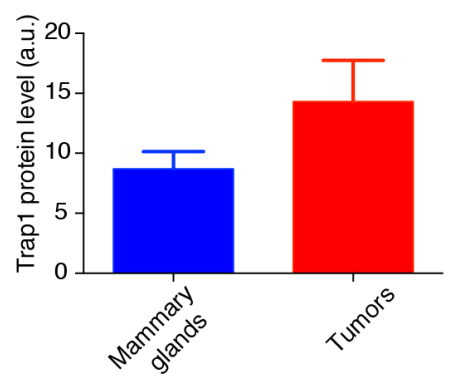

$\mathbf{F}$

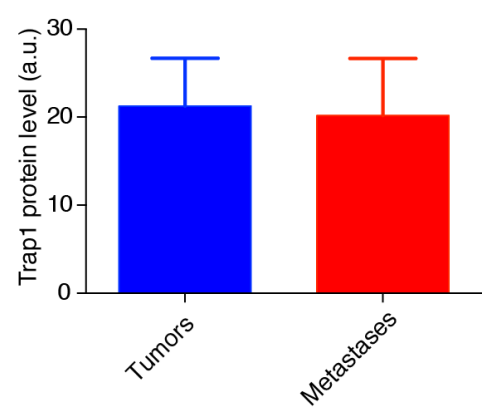

Figure 1: Expression levels of Hsp90 $\alpha$ and Trap1 in mammary tumors and metastatic nodules. A. Immunoblot showing Hsp90 $\alpha$ and Trap1 protein levels in mammary glands (M.G) derived from mice without the PyMT transgene $(n=3)$ and tumors from mice expressing the PyMT transgene $(n=5)$; actin was used as loading control. B. and $\mathbf{C}$. Bar graphs with the quantitation of the immunoblots; a significant increase of Hsp90 $\alpha$ level in tumors is indicated by an asterisk $\left({ }^{*} p<0.05\right)$; note that the apparent increase of Trap1 in tumors is not statistically significant. D. Immunoblot showing protein levels of Hsp90 $\alpha$ and Trap1 in tumors (T), metastatic nodules (M) and normal lung tissue (L) from two mice with the PyMT transgene; proper dissection of normal lung tissue was confirmed by the absence of PyMT; actin was used as loading control. E. and F. Quantitation of the immunoblots; comparing metastatic nodules and tumors, Hsp90 $\alpha$ levels do not change in a statistically significant manner $(n=6$ mice) nor do Trap1 levels $(n=5)$. 
Hsp90a

A

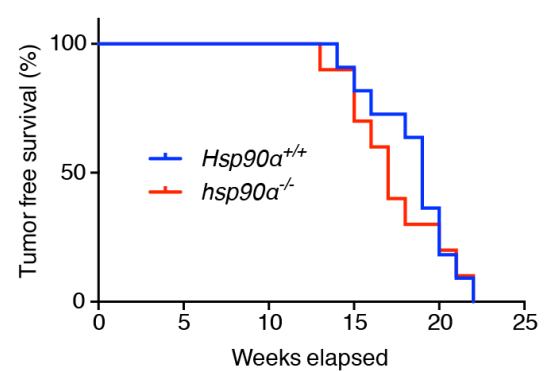

B

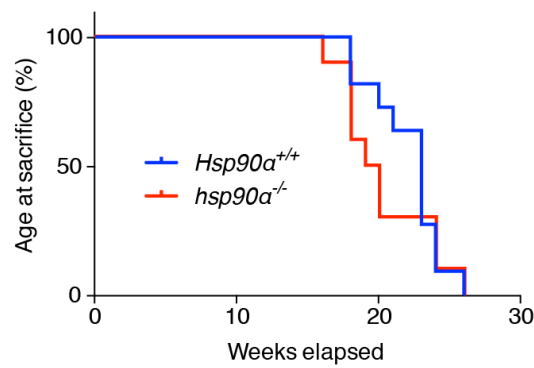

C

D

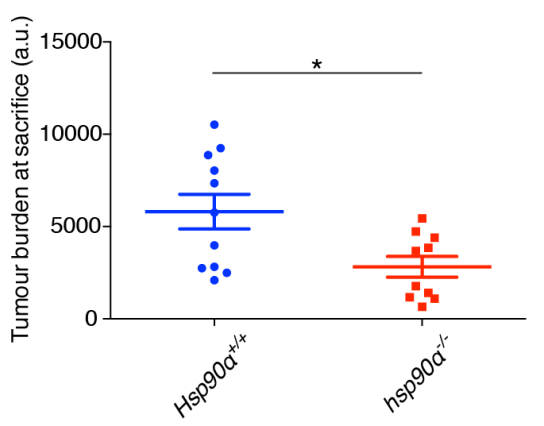

E
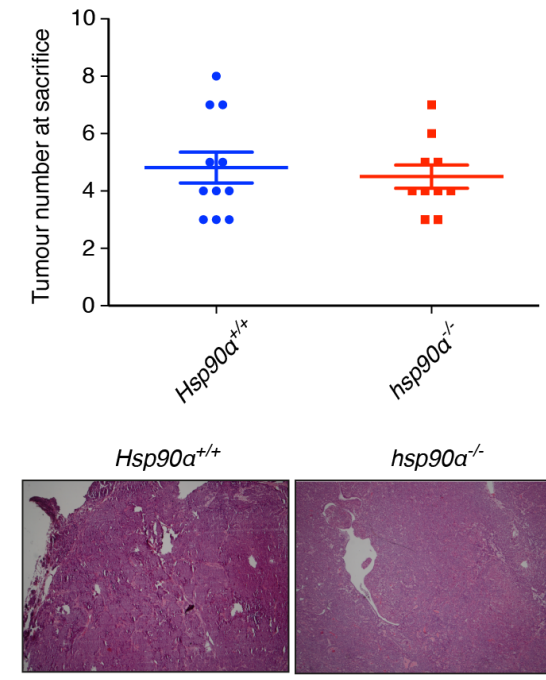

F

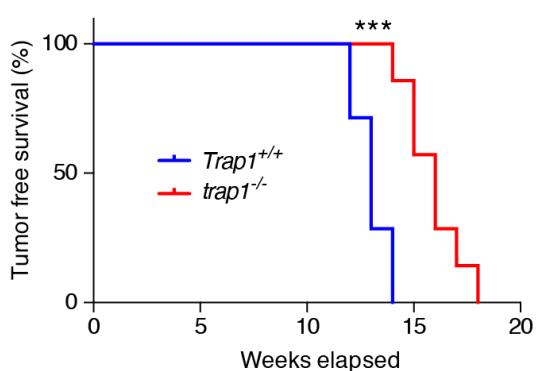

G

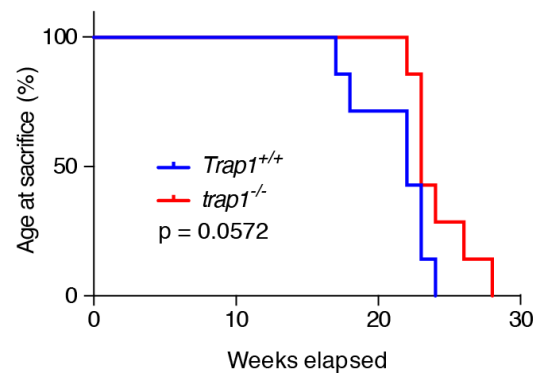

H

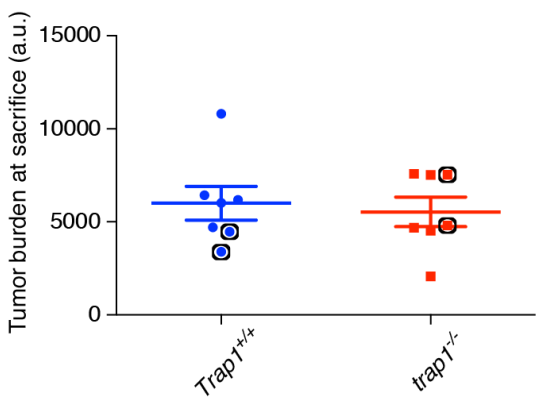

I

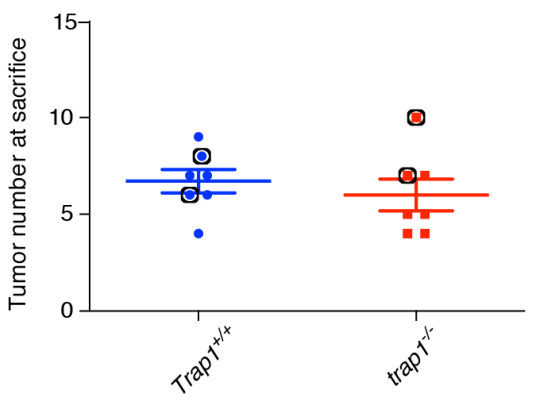

J

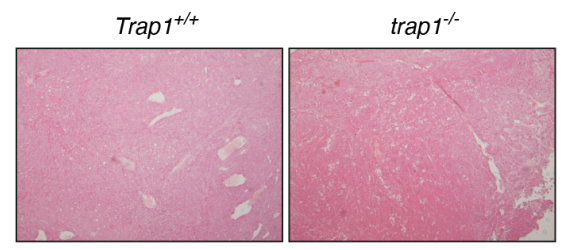

Figure 2: Effects of deleting the $\mathrm{Hsp} \mathbf{9 0} \alpha$ and Trap1 genes on tumor onset and growth. A. to E. Comparisons between $H s p 90 \alpha^{+/+}$ and $h s p 90 \alpha^{-\digamma}$ mice. Kaplan-Meier curves showing no difference in (A.) tumor free survival and (B.) age at sacrifice. C. Significant decrease in tumor burden in $h s p 90 \alpha^{-/}$mice at sacrifice $\left({ }^{*} p<0.05\right)$. D. No difference in tumor numbers at sacrifice. E. Tumor histology assessed by $\mathrm{H} \& \mathrm{E}$ indicating no difference (magnification $\mathrm{x} 40$, representative images are shown). F. to J. Comparisons between Trap $1^{+/+}$and $\operatorname{trap}^{-1 /}$ mice. F. Significantly longer tumor-free survival of $\operatorname{trap} 1^{-/}$mice $(* * * p<0.001)$; note that the seemingly more rapid tumor development

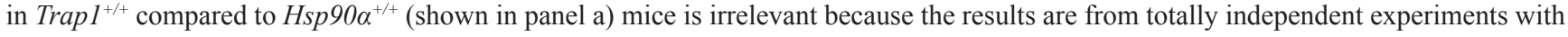
separate and non-comparable wild-type littermates. G. trap $1^{1 /}$ mice showed a trend towards longer overall survival $(p=0.0572)$. H. Similar tumor burden at sacrifice. I. No difference in tumor numbers at sacrifice. Indicated with black circles are the mice from which primary cells were isolated (see Figure 4). J. Tumor histology indicating no difference (magnification x40, representative images are shown). 
(Supplementary Figure 2B). Metastatic nodules could be clearly distinguished by $H \& E$ staining, and the presence of the PyMT antigen could be detected by immunohistochemistry (Figure 3A and D). On average, the loss of Hsp90 $\alpha$ resulted in a significant decrease in the total area and number of metastatic nodules (Figure $3 \mathrm{~B}$ and $\mathrm{C}$ ), even though there were large individual differences. However, no significant differences were observed in the lungs with depletion of Trap1, neither for the area of metastasis nor for the number of the metastatic nodules (Figure 3E and F). These results indicate an important role for the cytosolic Hsp90 isoform Hsp90 $\alpha$ in the metastatic process.

\section{Isolated mammary tumor cells display decreased proliferation in the absence of Hsp90 $\alpha$ or Trap1}

To improve our understanding of the molecular and cellular defects underlying our observations in the mouse model, we decided to characterize primary cells derived from tumors in vitro. We confirmed the epithelial origin of the isolated cells by probing immunoblots of cell extracts of all independent cellular isolates for the epithelial marker E-cadherin and for the mesenchymal marker vimentin (Figure 4A and C). Due to the lower tumor burden in $h s p 90 \alpha^{-/}$mice and the delay in tumor onset in trap $^{-1-}$ animals, we determined the proliferation rates of isolated cells. Interestingly, $h s p 90 \alpha^{-/}$cells exhibited significant growth retardation at 48 and 72 hours post seeding (Figure 4B), and similar observations were made for trap $1^{-/}$cells at 48, 72 and 96 hours post seeding (Figure 4D). Reduced cell numbers were clearly due to reduced proliferation rather than cell death since cells were counted after counterstaining dead ones with trypan blue. These results with isolated primary mammary tumor cells are consistent with an important role of Hsp90 $\alpha$ for mammary tumor growth and Trap1 in mammary tumor onset.

\section{Mouse mammary tumor cells do not secrete Hsp90a}

eHsp90, notably eHsp90 $\alpha$, has been suggested to play an important role for breast cancer cells to stimulate migration [12]. We therefore assessed the potential contribution of eHsp90 to the migratory behavior of our primary mouse carcinoma cells. Unexpectedly, we were unable to detect the presence of eHsp90 $\alpha$ in conditioned media of $H s p 90 \alpha^{+/+}$and $h s p 90 \alpha^{-/}$cells (Figure 5A). In contrast, eHsp90 $\alpha$ from human MDAMB-231 breast cancer cells was readily detectable, along with secretion of some Hsp90 $\beta$ from all three mouse cell lines. We further explored the possible involvement of eHsp90 pharmacologically by treating cells with the cell-impermeable Hsp90 inhibitor STA-12-7191 [38]. In the scratch assay shown in Figure 5B, both untreated wild-type $\left(H s p 90 \alpha^{+/+}\right)$cells and cells treated with STA12-7191 had a comparable capacity for migration. When MDA-MB-231 cells were used for a control experiment, the migration of these cells was significantly reduced by this inhibitor (Supplementary Figure 3), as previously described [38]. These experiments confirm the absence of functionally relevant eHsp90 $\alpha$, in particular, and eHsp90, in general, in $H_{s p} 90 \alpha^{+/+}$mouse carcinoma cells.

\section{Compromised cell migration and invasion in mammary tumor cells without Hsp90a or Trap1}

We wanted to check if the proliferation defect of hsp $90 \alpha^{-/}$and trap $^{-/}$cells was accompanied by a change in migration and invasion of these cells. Therefore, we performed a scratch assay to compare the cells of different genotypes. Indeed, the absence of Hsp90 $\alpha$ and Trap 1 reduced the migration ability of mammary tumor cells, as both $h s p 90 \alpha^{-/}$and trap $^{-/}$cells were significantly less efficient in wound closing (Figure 5B, $\mathrm{C}$ and $\mathrm{F}, \mathrm{G}$, respectively). To study the invasive potential of the isolated cells, we used a transwell invasion assay. Compared to $H_{s p} 90 \alpha^{+/+}$and Trap $1^{+/+}$cells, which were able to invade through the matrigel matrix into the lower chamber within 24 hours, both $h s p 90 \alpha^{-/}$and trap $1^{-/}$cells displayed a significantly compromised invasive capacity (Figure 5D, E and H, I). These results indicate that the absence of Hsp90 $\alpha$ or Trap1 impairs both migration and invasion of mouse mammary tumor cells.

\section{Correlation between higher levels of $H \operatorname{sp} 90 \alpha$ and bad prognosis in human breast cancer}

Having found that Hsp90 $\alpha$ and Trap1 play a role in one particular mouse mammary cancer model, we wondered to what extent one could extrapolate to human breast cancer. As a first step towards this goal, we set out to investigate whether expression levels could be correlated with breast cancer features. For this purpose, we utilized the online tool "Gene Expression-Based Outcome for Breast Cancer" Online (GOBO) [39]. This tool allows one to interrogate a large and very diverse dataset of breast cancers for such correlations. One important caveat is that the underlying data are mRNA and not protein levels. With that in mind, the GOBO analysis revealed significantly reduced time of overall and relapse-free survival for patients with higher $H s p 90 \alpha$ mRNA levels (Figure 6A and B), and therefore presumably Hsp $90 \alpha$ protein levels, along with a correlation of significantly increased $H s p 90 \alpha$ expression and higher tumor grade (Figure 6C). A similar analysis also revealed that increased Trapl expression is associated with higher tumor grade (Figure 6F), but failed to indicate a significant correlation with overall or relapse-free survival (Figure 6D and E). These findings are generally in agreement with the Hsp90 $\alpha$ mouse 
A

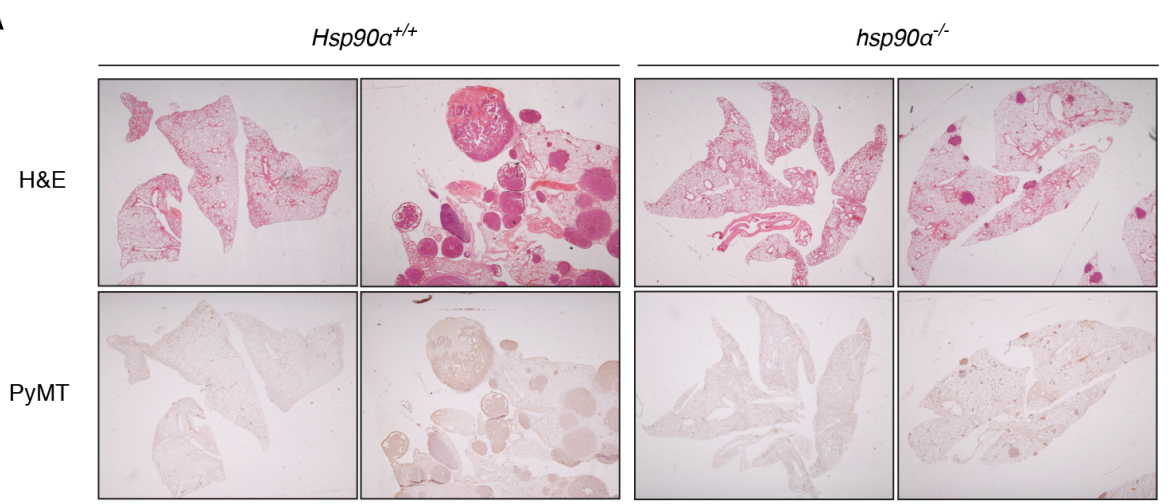

B

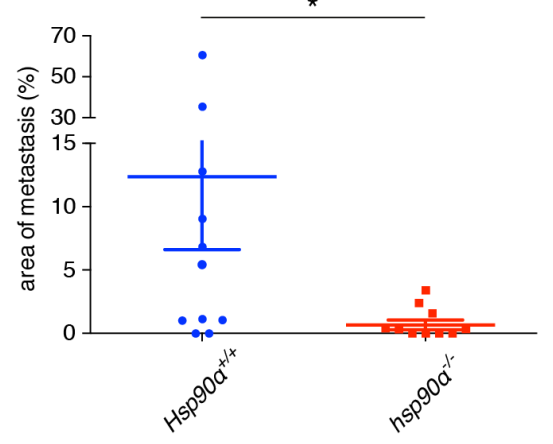

D

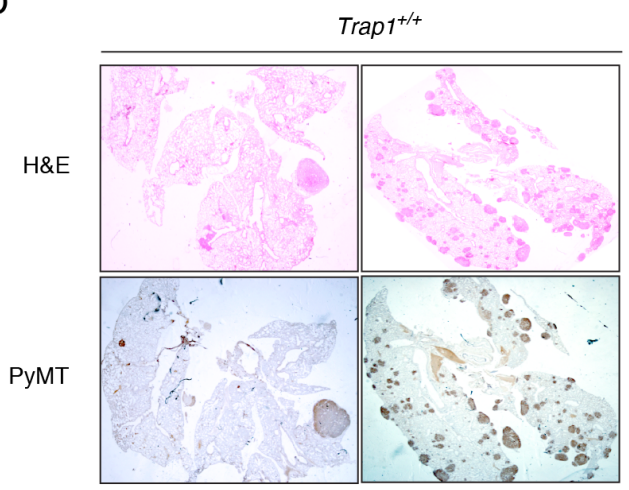

C

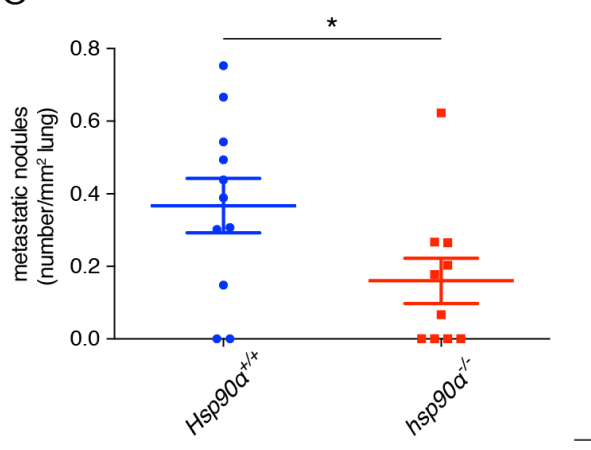

1
$\frac{1}{8}$
8
8
8

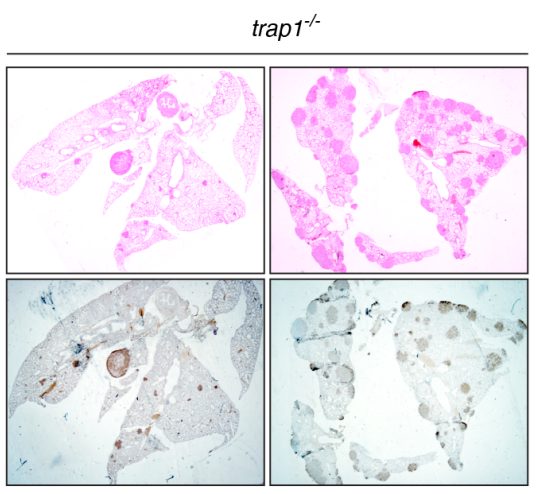

$\overrightarrow{\vec{g}}$
$\mathrm{E}$

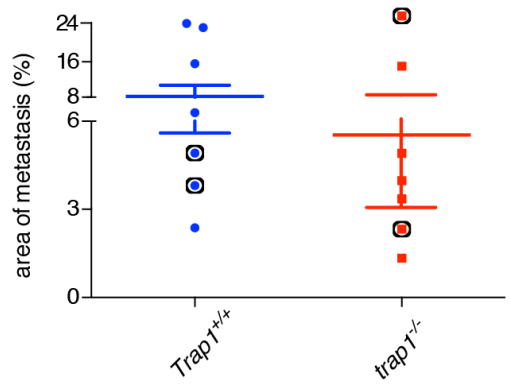

$\mathrm{F}$

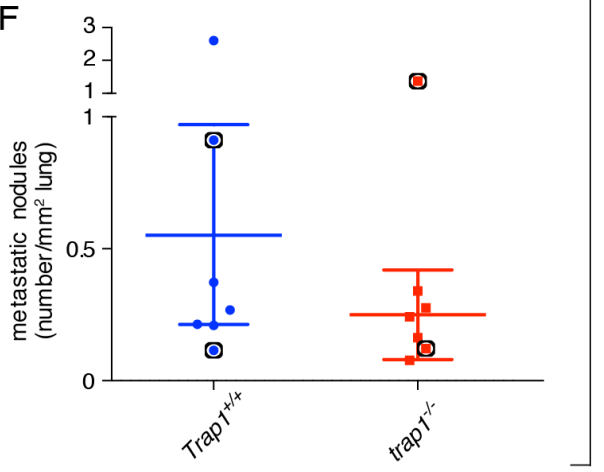

Figure 3: Effects of deleting the Hsp90a and Trap1 genes on lung metastasis. A. and D. H\&E staining (upper panel) and immunohistochemical staining for the PyMT antigen (lower panel) in whole lung sections of mice with the indicated genotypes (magnification $\mathrm{x} 10$, representative images are shown). B. Significant decrease in the metastatic area of $h s p 90 \alpha^{-1-}$ lungs $\left({ }^{*} p<0.05\right)$. C. Significant decrease in the total number of metastatic nodules in $h s p 90 \alpha^{-/}$lungs $(* p<0.05)$. E. No difference in the area of metastasis

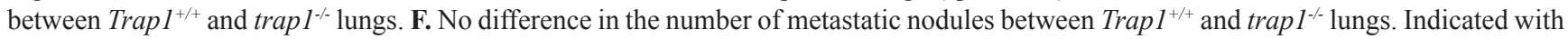
black circles are the mice from which primary cells were isolated (see Figure 4). 
A

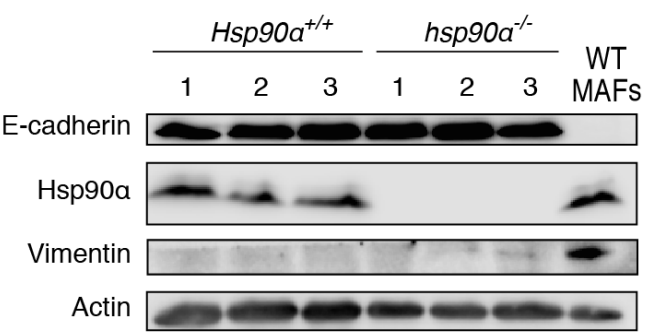

B

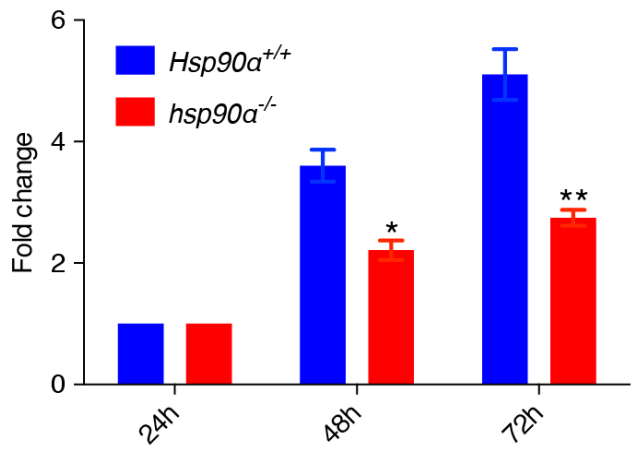

$I$
$\frac{1}{8}$
0
0
0

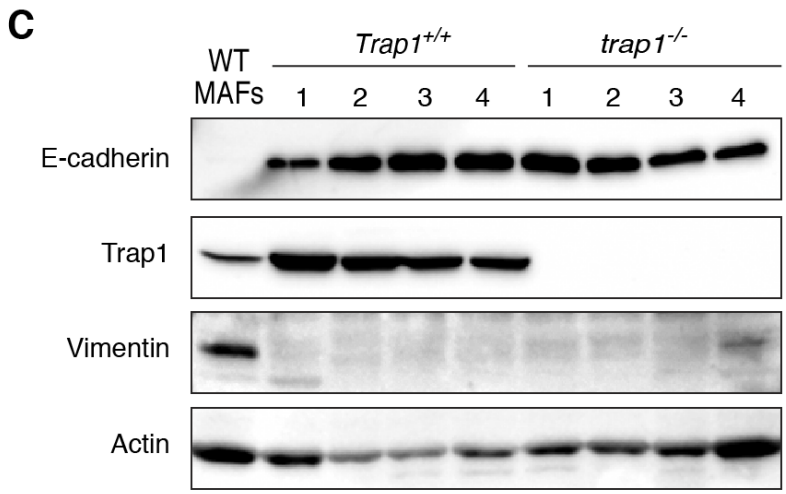

D

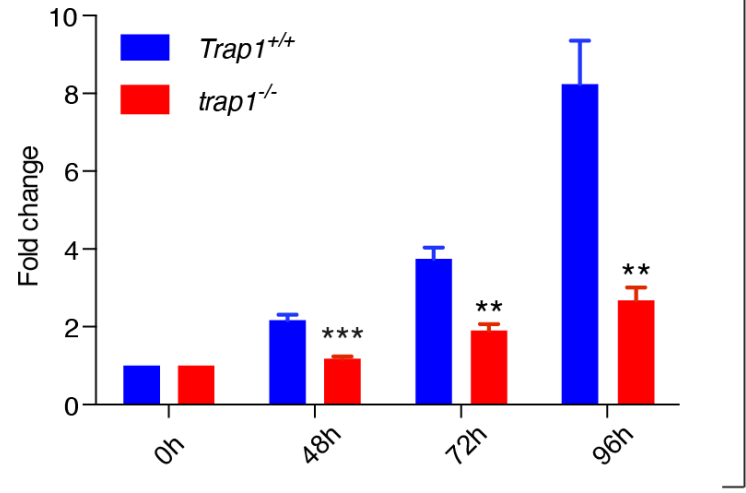

Figure 4: $h s p 90 \alpha^{-/}$and trap ${ }^{-/}$cells of epithelial origin derived from mammary tumors show decreased proliferation. A. and C. Immunoblots confirming epithelial origin of isolated cells, showing expression of E-cadherin and lack of expression of vimentin; cells were isolated from $3 \mathrm{Hsp} 90 \alpha^{+/+}$and $3 \mathrm{hsp} 90 \alpha^{-/}$mice, $2 \operatorname{Trap~}^{+/+}$and 2 trap $1^{-\leftarrow}$ animals (2 tumors per mouse); protein extracts from primary mouse adult fibroblasts (MAFs) were used as a positive control for vimentin expression; actin was used as loading control. B. $h s p 90 \alpha^{-/}$cells exhibited a significant decrease in growth rates (measured by MTT assay) at $48\left({ }^{*} p<0.05\right)$ and 72 hours $(* * p<0.01)$ after seeding. D. A decrease in proliferation rates was observed in trap $1^{-/}$cells (measured by standard cell counting) at $48(* * * p<0.001)$, $72\left({ }^{* *} p<0.01\right)$ and 96 hours $\left({ }^{* *} p<0.01\right)$ post seeding; results of three independent experiments are illustrated as a fold change to the absorbance at 24 hours after seeding (Hsp90 $\alpha$ ) or to the number of cells seeded (Trap1). 
Hsp90a

A

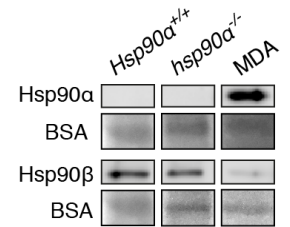

B

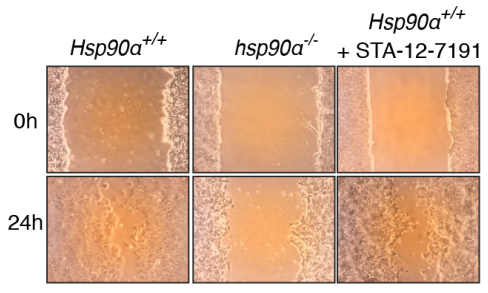

C

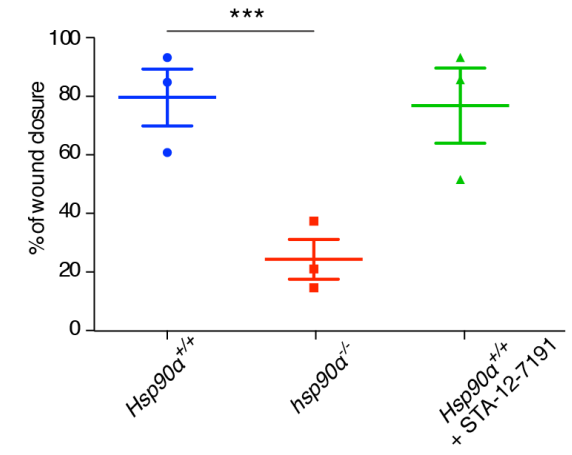

D

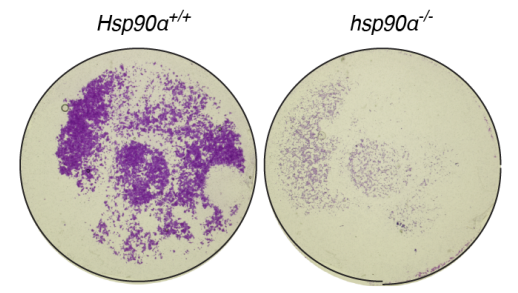

E

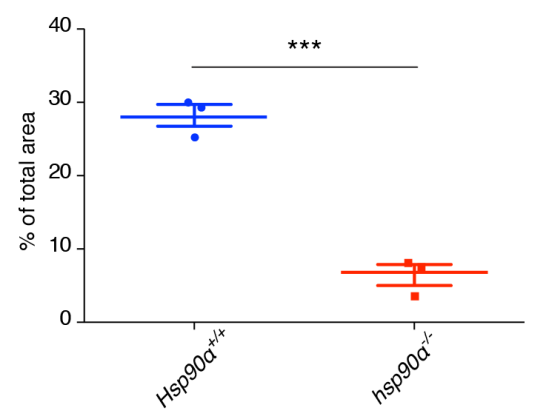

Trap1

$\mathbf{F}$

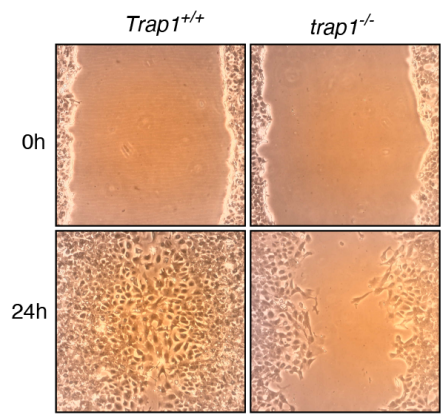

G

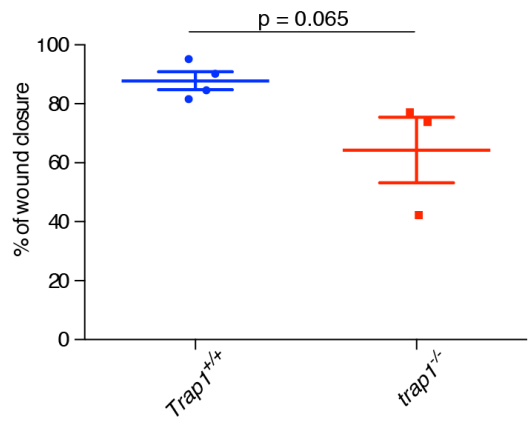

H

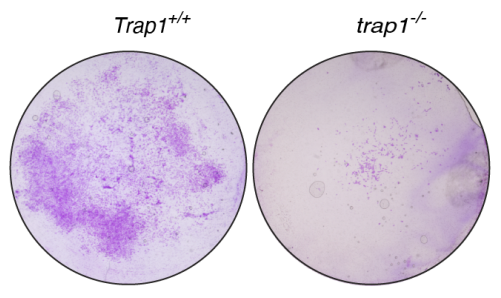

I

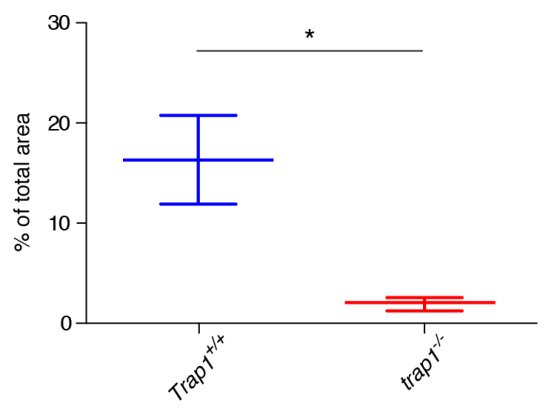

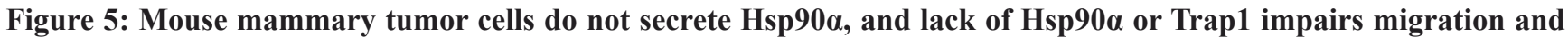
invasion. A. Immunoblot showing the absence of $\mathrm{Hsp} 90 \alpha$, but the presence of some Hsp90 $\beta$, in conditioned media from $H s p 90 \alpha^{+/+}$and hsp $90 \alpha^{-/}$cells; human MDA-MB-321 breast cancer cells served as positive control for Hsp90 $\alpha$ secretion; BSA present in the medium served as loading control. B. and C. Scratch assay on plastic plates indicating significantly reduced migration ability of $h s p 90 \alpha^{-/-}$cells $(* * * p<0.001)$, but not of $H s p 90 \alpha^{+/+}$cells treated with the cell-impermeable Hsp90 inhibitor STA-12-7191 (100 nM). Micrographs D. and quantitation E. of transwell assays $(* * * p<0.001)$. F. and G. Scratch assay with trap $1^{-/}$cells showing a trend towards decreased migration $(p=0.065)$. H. and I. Transwell assay demonstrating that trap $1^{-/}$cells were significantly less invasive $(* p<0.05)$; two images per scratch at 0 and 24 hours were taken at 40x magnification with a Dino-lite camera (AnMo Electronics Corporation); the software ImageJ was used to measure the width of the scratches at five points per picture; for transwell assay photos were taken using a stereo microscope (15x magnification); Images resulting from duplicates of three independent experiments were quantified by ImageJ. 
experiments described above, and highlight the importance of Hsp90 $\alpha$ for breast cancer development and metastasis in both mice and humans. In contrast, the results obtained for Trap 1 require further investigations to clarify exactly which human breast cancer type may be represented by the mouse model with respect to Trap1.

\section{DISCUSSION}

Hsp90 has been investigated for many years as a potential player involved in cancer pathogenesis; however, the exact details of its mode of action still remain elusive. Even less is known about the role of Trap1 in tumorigenesis. We aimed to address the issue of Hsp90 $\alpha$ and Trap1 involvement specifically in breast cancer initiation, progression and metastasis by using an in vivo mouse breast cancer model. Such a mouse model provides more relevant information than previously described experiments with cancer cell lines and xenografts. We found that neither Hsp90 $\alpha$ nor Trap1 are absolutely required for mammary tumorigenesis and metastasis, but have striking modulatory effects.

An important limitation of our approach that must be kept in mind is that the query proteins Hsp $90 \alpha$ or Trap 1 were absent both from the mammary epithelial cells, i.e. the tumor cells, and the stroma at the primary tumor site and all the way to the metastatic sites in the lung. Recent xenograft experiments have revealed a requirement for Hsp90 $\alpha$ in the host for the colonization of the lung by Hsp90 $\alpha$-positive melanoma cells [40]. In the future, the challenge will be to dissect the functional importance of Hsp90 $\alpha$ and Trap1 separately in the tumor cells, in the stroma and in the metastatic niche across a panel of tumor models.

\section{Could Trap1 and Hsp90a be redundant?}

The fact that these molecular chaperones are not absolutely required in our mouse tumor model could formally be due to functional redundancy. While we cannot formally exclude this, there is no experimental evidence to support it. Trap1 and Hsp90 $\alpha$ being only $29 \%$ identical, it is not very likely that they could replace each other, were they to be localized in each other's compartments. Trap1 is synthesized with an N-terminal mitochondrial targeting signal, but some "cytosolic" Hsp90 was reported to be present in mitochondria [27]. If this is also the case in our tumor model, then clearly it is insufficient to suppress all of the phenotype associated with the absence of Trap1. Moreover, the same authors argued that the effects of a Trap1 knock-down and of pharmacologically inhibiting mitochondrial Trap1 are the same [27]; one must conclude from these results that Trap1 and mitochondrially localized cytosolic Hsp90 are not functionally redundant, since the latter would also have been inhibited in mitochondria by the same inhibitor.

\section{Tumor initiation and growth}

In the absence of Hsp90 $\alpha$, even though we did not observe any changes in the time of tumor initiation and age of mice at sacrifice, impaired tumor growth was apparent. Lack of Hsp90 $\alpha$ made a difference for the dynamics of tumor growth, as $h s p 90 \alpha^{-\alpha}$ mice showed a decrease in tumor burden, albeit not in tumor numbers. Further supporting this observation, Hsp $90 \alpha$-null cells isolated from primary mammary tumors had slower proliferation rates. These results can be related to previous reports on the inhibitory effects of Hsp90 inhibitors on breast cancer cell growth in mouse xenograft models [41-44] and in clinical trials $[45,46]$. In addition, we also found that the protein levels of Hsp90 $\alpha$ were significantly elevated in tumors compared to normal mammary glands, a finding compatible with our conclusion that Hsp90 $\alpha$ contributes to breast cancer growth.

As far as the mitochondrial Hsp90 isoform Trap1 is concerned, despite its increased levels in tumors compared to normal mammary glands, tumors still formed even in its complete absence. However, we saw a delay in the tumor

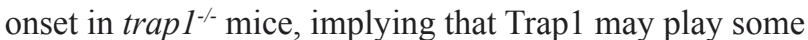
facilitating role in tumor initiation. It is conceivable that trap $1^{-/}$tumor cells might be slow at boosting their initially potentially lower glycolysis [23] as part of their metabolic adaptation to the tumorigenic process. Eventually, at sacrifice, total tumor burden appeared similar between the two groups, indicating that beyond tumor initiation Trap1 is dispensable for subsequent tumor growth. We assume that the trend towards longer overall survival of trap $1^{-/-}$ mice may be due to the observed delay in tumor initiation. In apparent contradiction to what we observed with our genetic model, pharmacological inhibition of Trap1 and TRAP1 deletion in a prostate cancer model resulted in inhibition of tumor growth [47, 48] and reduced tumor incidence [49], respectively. In previously reported xenograft assays performed with SAOS-2 osteosarcoma cells [50], MDA-MB-231 and MCF-7 breast cancer cells [29], and human esophageal cancer cells [51], knocking down Trap1 by RNA interference resulted in decreased tumor growth. Intriguingly, this mirrors the reduced proliferation rates, which we observed for mammary tumor cells isolated from trap $^{-/}$mice. The apparent discrepancies further highlight the already known contextual role of Trap1 [21]. Further investigations will be necessary to dissect the contributions of Trap1 and its impact on cellular metabolism to the different stages of tumor growth, from the earliest stages of tumor initiation to the growth dynamics of tumor masses.

\section{Metastasis}

In view of the proposed role of eHsp90 $\alpha$ in promoting migration and invasion of cancer cells $[7,12$, 
A

Hsp90a

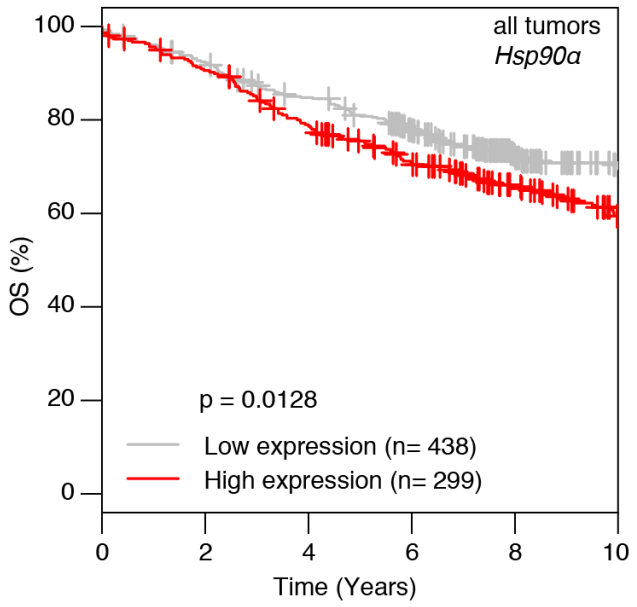

B

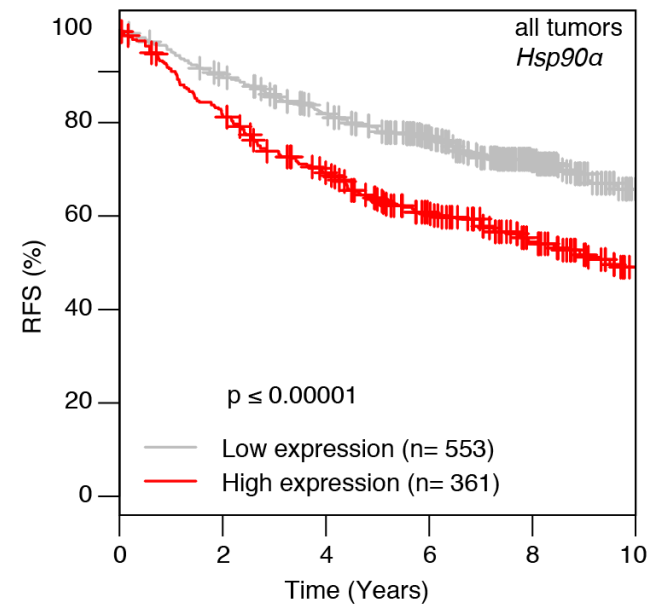

C

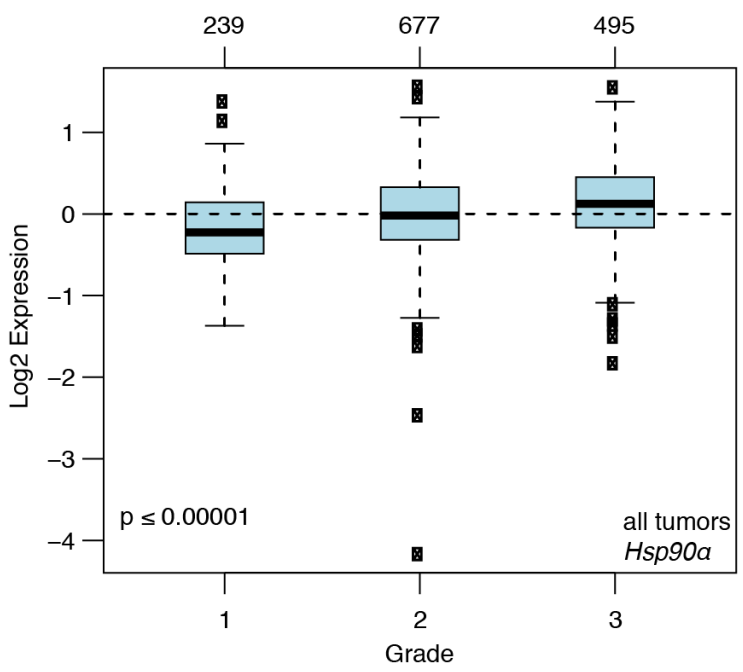

Trap1

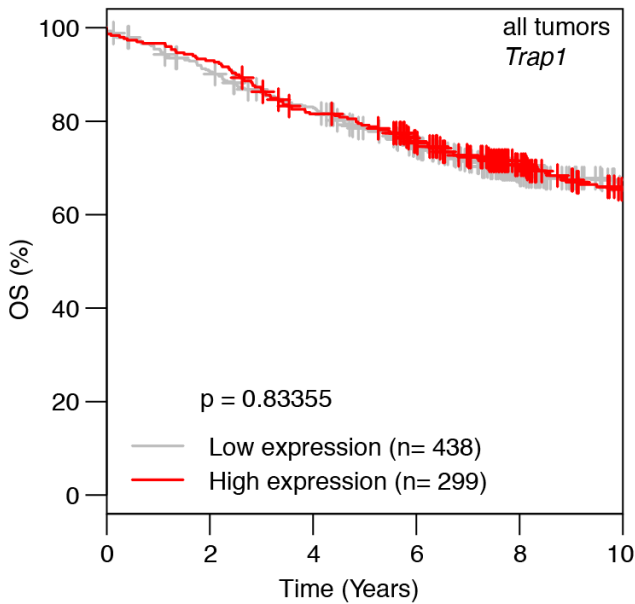

E

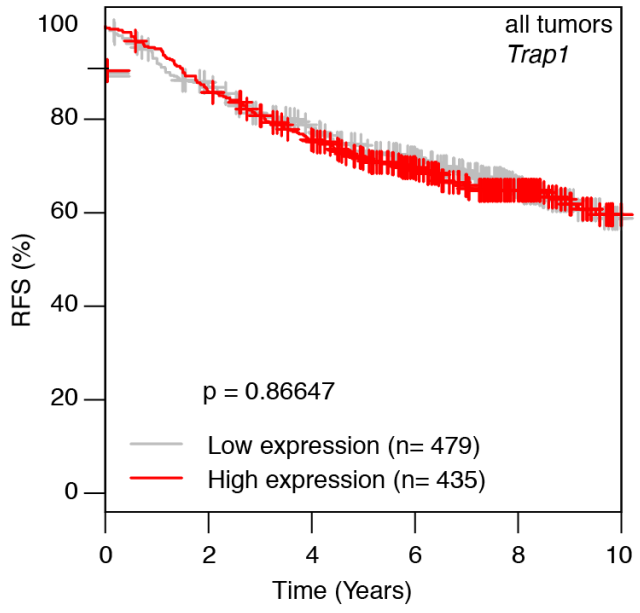

$\mathbf{F}$

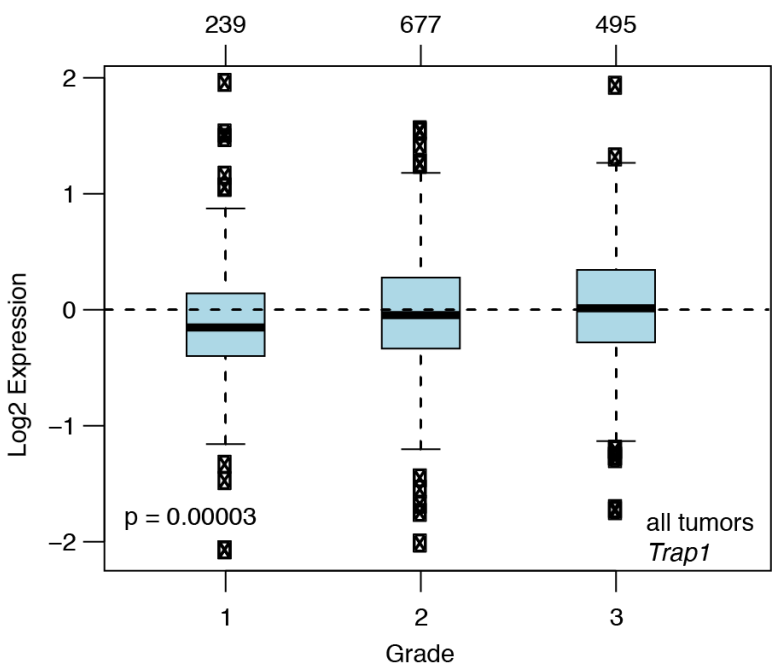

Figure 6: Correlation of higher $H s p 90 \alpha$ mRNA expression with worse prognosis in human breast cancer revealed by a GOBO analysis. A. and B. Higher Hsp $90 \alpha$ expression is associated with significant decrease in overall survival (A. $p=0.0128$ ) and relapse free survival (B. $p \leq 0.00001)$. C. Higher Hsp $90 \alpha$ expression correlates with increase in tumor grade $(p<0.00001)$. D. and E. Trap 1 mRNA expression and overall and relapse free survival show no correlation. F. Increase in Trapl expression is associated with higher tumor grade $(p=0.00003)$. 
$14,38,52]$, we were particularly interested in determining the impact of Hsp90 $\alpha$ ablation on the rate and extent of metastasis. We discovered that, while Hsp90 $\alpha$ is not absolutely required for metastasis, mice lacking Hsp90 $\alpha$ developed pulmonary metastatic nodules less frequently than their wild-type counterparts; $h s p 90 \alpha^{-/-}$mice also displayed lower numbers and smaller areas of metastatic nodules in the lungs. Furthermore, the migratory and invasive potential of cells isolated from primary mammary tumors was significantly decreased in cells lacking Hsp90 $\alpha$. These results point to an important role of Hsp90 $\alpha$ for the metastatic progression and are in line with previous reports on Hsp90 acting as a potent enhancer of migration and invasion [7, 38, 52-59]. It has been speculated that some effects of Hsp90 inhibitors could be the result of the inhibition of eHsp90 rather than or in addition to the inhibition of intracellular Hsp90 [12, 17]. It is certainly reasonable to hypothesize that intracellular and extracellular pools of Hsp90 molecules perform distinct functions. Given that we could not detect appreciable amounts of eHsp90 $\alpha$ with primary mammary tumor cells from wild-type mice, any Hsp90 $\alpha$ function is most likely attributable to intracellular Hsp90 $\alpha$. It should also be emphasized that secretion of the other isoform, Hsp90 $\beta$, which we could detect, obviously did not compensate either. The dependence on secreted Hsp90 and the signals such as stress and activated oncogenes that promote this secretion may vary from cancer to cancer $[12,17]$. It is possible that the transformation by the PyMT oncogene in our particular model does not stimulate the secretion of Hsp90 $\alpha$. Hence, and although we cannot formally exclude that these same cells do secrete eHsp90 $\alpha$ when they are within the context of a tumor in the mouse, we conclude that the observed growth, migratory and invasive defects of Hsp90 $\alpha$-null mammary tumor cells must be due to the lack of intracellular Hsp90 $\alpha$. Whatever the contribution of eHsp90 to human cancers may be, in our murine breast cancer model, it is the absence of intracellular Hsp90 $\alpha$, which compromises tumor progression and metastasis. The fact that metastatic tumors can still form in the absence of Hsp90 $\alpha$ at all is intriguing. This may be due to compensatory mechanisms that are stochastically switched on in a small subset of cells. This might involve a permanent or temporary upregulation of expression or activity of the other Hsp90 isoform, Hsp90ß, or of other cancer-relevant cellular processes.

For Trap1, differences between in vivo and in vitro results indicate a more complex situation. In the mouse, pulmonary metastases formed equally in both experimental groups, although there was a big intragroup variation. However, trap $1^{-/}$primary mammary tumor cells in culture showed a trend for slower migration and a strong defect in invasion. These differences are not related to the metastatic status of the mice from which the cells were isolated; as mentioned before, $\operatorname{Trap}^{+/+}$cells were obtained from animals that did not display the highest metastatic burden, whereas trap $1^{-/-}$cells were derived from mice with very different metastatic loads. These results may indicate substantially different requirements in vivo versus in vitro regarding the cellular energy metabolism. In agreement with our results, Trap1 appears to promote cell migration and invasion in human esophageal squamous cell cancer [60]. However, these results contradict what we have previously found ourselves with trap $^{-/-}$mouse adult fibroblasts, and with HCT116 and HeLa cells depleted of Trap1 by RNA interference; these cells performed considerably better in a transwell assay [23]. Similarly, it has recently been published that invasive breast cancer cell lines have lower levels of Trap1; the same investigators found that when Trap1 is overexpressed in the invasive cell line MDA-MB-231 and cells are injected into the tail vein of immunodeficient mice, metastasis is inhibited [29]. Once again, as for primary tumor growth, context seems to be crucial for Trap1. The challenge for the future will be to carefully clarify the role of Trap 1 in metastasis for different types of cancers both in tissue culture and in in vivo mouse models.

\section{Relevance to human breast cancer}

A major difficulty in extrapolating from experimental data from a few cell lines to human cancer is their singularity. Using the online tool GOBO we found that an increase in $H s p 90 \alpha$ mRNA levels correlated with bad prognosis in breast cancer patients. This is in agreement with previously reported findings for non-small cell lung cancer [61], cells from acute myeloid leukemia patients [62] and gastric cancer patients [63]. Contrary to what we observed in the mouse model, in patients there is no correlation between tumor-free or overall survival and Trap1 mRNA levels. However, higher Trap1 expression correlated with higher tumor grade, which mirrors the functional relationship between Trapl and tumor onset seen in our mouse model.

Overall, our findings provide further evidence for an important role of Hsp90 $\alpha$ in breast cancer progression not only in our mouse model but also in human breast cancer patients. They corroborate the notion that Hsp90 should be considered as a target in anti-cancer treatment strategies. For Trap1, our results further emphasize the importance of the context and support the argument that targeting Trap1 may not be beneficial in all types of cancer at all stages and in all circumstances.

\section{MATERIALS AND METHODS}

\section{Animals}

Mice were housed under standard conditions, and all animal experiments were conducted in compliance with 
Swiss laws. The generation of the $h s p 90 \alpha^{-/}$mutant mouse strain ( $h$ sp90aal $^{G t(X E 444) B y g}$ ) and the genotyping primers for this strain have been previously described [34]. trap1 - mice, derived from the ES cell clone E041F05, were obtained from the German Gene Trap Consortium. The Trapl gene disruption is due to the insertion of a gene trap cassette (vector rFlipROSAßgeo +1 ) in the first intron of the gene (trap ${ }^{G t(E 041 F 05) W r s t}$ allele). Genotyping: PCR with forward primer 5'-gtcaagcctggggtaactacgg-3' and reverse primer 5'-cactttaatcctaccactctgggg-3' gives a band of $606 \mathrm{bp}$ for the wild-type Trapl allele; PCR with forward primer 5'-aggggtctccegatcccg-3' and reverse primer 5'-cactttaatcctaccactctgggg-3' gives a band of 538 bp for the mutated trap $1^{\text {Gt(E041F05)Wrst }}$ allele. FVB/N-Tg(MMTVPyVT)634Mul/J (PyMT) transgenic mice [32] were a gift from Dr. Agnese Mariotti's laboratory (CHUV, University of Lausanne, Lausanne, Switzerland). Hsp $90 \alpha^{+/ /} / \mathrm{PyMT}$ males were crossed with $H s p 90 \alpha^{+/}$females to generate $H s p 90 \alpha^{+/+} /$PyMT and $h s p 90 \alpha^{-/ /} /$PyMT females used for the analysis. Trap 1/trap 1 ${ }^{\text {Gt(E041F05)Wrst/PyMT males were crossed }}$ with Trap1/trap $1^{\text {Gt(E041F05)Wrst }}$ females to generate Trap $1^{+/+} /$ $P y M T$ and rrap $^{-/-} / P y M T$ females used for the analysis.

\section{Evaluation of tumors, tissue collection, histology and immunohistochemistry}

From the age of 30 days, the development of mammary tumors in female mice carrying the PyMT transgene was followed by palpation for the appearance of the multifocal mammary adenocarcinomas thrice a week. When the tumors reached the legal size, mice were euthanized, number and size of tumors were determined, and tumors and lungs were collected and further processed. "Tumor number" represents the number of adenocarcinoma foci per mouse; "tumor burden" is defined as the total volume of the detectable tumor foci per mouse, a correlative measure of the number of cancer cells. Paraffin sections of tumors and lungs were subjected to $\mathrm{H} \& \mathrm{E}$ or immunohistochemical staining according to standard protocols using an anti-PyMT antibody (sc53481; Santa Cruz Biotechnology).

\section{Histomorphometric analysis}

For measurements of total areas of lung metastasis, four $5 \mu \mathrm{m}$ thick sections separated by $100 \mu \mathrm{m}$ were stained with H\&E and photographed using a stereo microscope. The software ImageJ was used to calculate the total area and number of metastatic nodules normalized to the total lung area. Slides with adjacent sections stained with the PyMT antibody allowed for a confirmation of the presence of metastatic sites.

\section{Isolation of primary epithelial cells from mouse mammary tumors}

Primary epithelial cells from mouse mammary tumors were isolated as previously described [64] and cultured in standard DMEM with $4.5 \mathrm{~g} / \mathrm{l}$ glucose and 10\% fetal bovine serum (FBS).

\section{Tissue and cell extracts and collection of conditioned media for immunoblotting}

Proteins were extracted from frozen tissues according to standard protocols. To collect secreted proteins, $H s p 90 \alpha^{+/+}$and $h s p 90 \alpha^{-/-}$primary cell lines or MDA-MB-231 cells were seeded at the same density in OPTI-MEM medium (ThermoFisher Scientific) with 2\% FBS; after 24 hours, cells were washed with PBS and grown for 48 hours in OPTI-MEM medium without FBS. Media were collected and centrifuged at $12000 \mathrm{rpm}$ for 20 minutes at $4^{\circ} \mathrm{C}$, supernatant was concentrated using centrifugal filter units (10 kDa cutoff, Amicon Ultra) according to manufacturer's instructions.

Equal amounts of protein extracts or $40 \mu \mathrm{l}$ of conditioned medium were subjected to SDS-PAGE followed by standard immunoblotting procedures. The following primary antibodies were used: antiHsp90 $\alpha$ (EMD-17D7, Merck Millipore), anti-Trap1/ Hsp75 (BD Biosciences), anti-Hsp90 $\beta$ (H9010, ThermoFisher Scientific), anti-Vimentin (PA5-27231; ThermoFisher Scientific), anti-E-cadherin (H-108, Santa Cruz Biotechnology), anti-PyMT antibody (sc-53481; Santa Cruz Biotechnology) and the pan-actin antibody C4 (Millipore). The secondary antibodies used were horseradish peroxidase-goat anti-rabbit or anti-mouse immunoglobulins (Dako).

\section{Proliferation assays}

$H s p 90 \alpha^{+/+}$and $h s p 90 \alpha^{-/}$cell proliferation was monitored by performing MTT assays with 3-(4,5-Dimethylthiazol-2-yl)-2,5-diphenyltetrazolium bromide (Applichem). The proliferation rate of Trap1 $1^{+/+}$

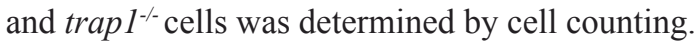

\section{Scratch assays}

Cells were seeded at equal densities in standard medium, allowed to attach and treated for 2 hours with 5 $\mu \mathrm{g} / \mathrm{ml}$ mitomycin C (Sigma). Afterwards, fresh standard medium without or with $100 \mathrm{nM}$ of the cell-impermeable Hsp90 inhibitor STA-12-7191 [38] was added and three scratches per well were made in the cell monolayer with a sterile yellow tip. 


\section{Transwell invasion assays}

Cells were treated with $5 \mu \mathrm{g} / \mathrm{ml}$ mitomycin (Sigma) for 2 hours, trypsinised and seeded at an equal density in DMEM without FBS in the upper chamber of the transwell chamber $(8 \mu \mathrm{m}$ pore size) on $30 \mu \mathrm{l}$ (Hsp90 $\alpha$ cells) or 50 $\mu \mathrm{l}$ (Trap1 cells) of matrigel ${ }^{\circledR}$ matrix $1.5 \mu \mathrm{g} / \mathrm{ml}$ (Corning). The lower chamber was filled with standard medium. After 24 hours, cells were fixed in methanol and stained with $0.5 \% \mathrm{w} / \mathrm{v}$ crystal violet (Sigma) in methanol. The filter was cut out of the chamber and mounted on a slide.

\section{GOBO analysis}

The online tool GOBO (Gene expression-based Outcome for Breast cancer Online) [39] was used to draw the correlation between expression of HSP90AA1 (Hsp90 $\alpha$ ) (Entrez Gene ID: 3320) and TRAP1 (Entrez Gene ID: 10131) and overall survival, relapse-free survival and tumor grade in microarray datasets of human breast cancer samples.

\section{Statistical analysis}

Statistical analysis was performed with GraphPad Prism 6. Long-rank (Mantel-Cox) was used for the analysis of the Kaplan-Meier survival curves. The rest of the datasets were subjected to normality tests and compared by parametric (t-test) or non-parametric (MannWhitney) tests. When $\mathrm{p}$-values were $\mathrm{p}<0.05$, differences were considered statistically significant. Error bars represent standard errors of the mean (SEM).

\section{ACKNOWLEDGMENTS}

We thank the personnel of the histology platform of the Centre Médical Universitaire at University of Geneva (Geneva, Switzerland) and Diana Wider for their technical assistance, Dr. Santosh Ghadge for his early efforts on this project, and Dr. Agnese Mariotti's laboratory (CHUV, University of Lausanne, Lausanne, Switzerland) for sharing with us the PyMT transgenic mouse line. WW was supported for this project by the Bundesministerium für Bildung und Forschung (BMBF) grant 'TAL-CutTechnology' (03V0261) and the Helmholtz Portfolio Theme 'Metabolic Dysfunction and Common Disease'. EV, MMS, SH, GM and DP were supported by the Swiss National Science Foundation and the Canton de Genève.

\section{CONFLICTS OF INTEREST}

The authors declare that they have no conflict of interest.

\section{REFERENCES}

1. Picard D. Preface to Hsp90. Biochim Biophys Acta. 2012; 1823: 605-606.

2. Prodromou C. Mechanisms of Hsp90 regulation. Biochem J. 2016; 473: 2439-2452.

3. Isaacs J, Whitesell L, editors. Hsp90 in cancer: beyond the usual suspects. Elsevier; 2016.

4. Zong H, Gozman A, Caldas-Lopes E, Taldone T, Sturgill E, Brennan S, Ochiana SO, Gomes-DaGama EM, Sen S, Rodina A, Koren J, 3rd, Becker MW, Rudin CM, et al. A hyperactive signalosome in acute myeloid leukemia drives addiction to a tumor-specific Hsp90 species. Cell Rep. 2015; 13: 2159-2173.

5. Whitesell L, Lindquist SL. HSP90 and the chaperoning of cancer. Nat Rev Cancer. 2005; 5: 761-772.

6. Vartholomaiou E, Echeverria PC, Picard D. Unusual suspects in the twilight zone between the Hsp90 interactome and carcinogenesis. Adv Cancer Res. 2016; 129: 1-30.

7. Eustace BK, Sakurai T, Stewart JK, Yimlamai D, Unger C, Zehetmeier C, Lain B, Torella C, Henning SW, Beste G, Scroggins BT, Neckers L, Ilag LL, et al. Functional proteomic screens reveal an essential extracellular role for hsp90 $\alpha$ in cancer cell invasiveness. Nat Cell Biol. 2004; 6: 507-514.

8. Wang X, Song X, Zhuo W, Fu Y, Shi H, Liang Y, Tong M, Chang G, Luo Y. The regulatory mechanism of Hsp90 $\alpha$ secretion and its function in tumor malignancy. Proc Natl Acad Sci USA. 2009; 106: 21288-21293.

9. Dong H, Zou M, Bhatia A, Jayaprakash P, Hofman F, Ying Q, Chen M, Woodley DT, Li W. Breast cancer MDAMB-231 cells use secreted heat shock protein-90alpha (Hsp90 $\alpha$ ) to survive a hostile hypoxic environment. Sci Rep. 2016; 6: 20605.

10. Bennesch MA, Segala G, Wider D, Picard D. LSD1 engages a corepressor complex for the activation of the estrogen receptor $\alpha$ by estrogen and cAMP. Nucleic Acids Res. 2016; 44: 8655-8670.

11. Zagouri F, Sergentanis TN, Chrysikos D, Papadimitriou CA, Dimopoulos MA, Psaltopoulou T. Hsp90 inhibitors in breast cancer: a systematic review. Breast. 2013; 22: 569578.

12. Li W, Sahu D, Tsen F. Secreted heat shock protein-90 (Hsp90) in wound healing and cancer. Biochim Biophys Acta. 2012; 1823: 730-741.

13. Stivarou T, Stellas D, Vartzi G, Thomaidou D, Patsavoudi E. Targeting highly expressed extracellular HSP90 in breast cancer stem cells inhibits tumor growth in vitro and in vivo. Cancer Biol Ther. 2016; 17: 799-812.

14. Tsutsumi S, Scroggins B, Koga F, Lee MJ, Trepel J, Felts S, Carreras C, Neckers L. A small molecule cell-impermeant Hsp90 antagonist inhibits tumor cell motility and invasion. Oncogene. 2008; 27: 2478-2487. 
15. Li W, Li Y, Guan S, Fan J, Cheng CF, Bright AM, Chinn C, Chen M, Woodley DT. Extracellular heat shock protein$90 \alpha$ : linking hypoxia to skin cell motility and wound healing. EMBO J. 2007; 26: 1221-1233.

16. Song X, Wang X, Zhuo W, Shi H, Feng D, Sun Y, Liang Y, Fu Y, Zhou D, Luo Y. The regulatory mechanism of extracellular Hsp90 $\alpha$ on matrix metalloproteinase-2 processing and tumor angiogenesis. J Biol Chem. 2010; 285: 40039-40049.

17. Li W, Tsen F, Sahu D, Bhatia A, Chen M, Multhoff G, Woodley DT. Extracellular Hsp90 (eHsp90) as the actual target in clinical trials: intentionally or unintentionally. Int Rev Cell Mol Biol. 2013; 303: 203-235.

18. Sahu D, Zhao Z, Tsen F, Cheng CF, Park R, Situ AJ, Dai J, Eginli A, Shams S, Chen M, Ulmer TS, Conti P, Woodley DT, et al. A potentially common peptide target in secreted heat shock protein- $90 \alpha$ for hypoxia-inducible factor- $1 \alpha$ positive tumors. Mol Biol Cell. 2012; 23: 602-613.

19. Felts SJ, Owen BA, Nguyen P, Trepel J, Donner DB, Toft DO. The Hsp90-related protein TRAP1 is a mitochondrial protein with distinct functional properties. J Biol Chem. 2000; 275: 3305-3312.

20. Altieri DC, Stein GS, Lian JB, Languino LR. TRAP-1, the mitochondrial Hsp90. Biochim Biophys Acta. 2012; 1823: 767-773.

21. Rasola A, Neckers L, Picard D. Mitochondrial oxidative phosphorylation TRAP(1)ped in tumor cells. Trends Cell Biol. 2014; 24: 455-463.

22. Vander Heiden MG, Cantley LC, Thompson CB. Understanding the Warburg effect: the metabolic requirements of cell proliferation. Science. 2009; 324: 1029-1033.

23. Yoshida S, Tsutsumi S, Muhlebach G, Sourbier C, Lee MJ, Lee SM, Vartholomaiou E, Tatokoro M, Beebe K, Miyajima N, Mohney RP, Chen Y, Hasumi H, et al. Molecular chaperone TRAP1 regulates a metabolic switch between mitochondrial respiration and aerobic glycolysis. Proc Natl Acad Sci USA. 2013; 110: E1604-E1612.

24. Landriscina M, Amoroso MR, Piscazzi A, Esposito F. Heat shock proteins, cell survival and drug resistance: the mitochondrial chaperone TRAP1, a potential novel target for ovarian cancer therapy. Gynecol Oncol. 2010; 117: 177182.

25. Costantino E, Maddalena F, Calise S, Piscazzi A, Tirino V, Fersini A, Ambrosi A, Neri V, Esposito F, Landriscina M. TRAP1, a novel mitochondrial chaperone responsible for multi-drug resistance and protection from apoptotis in human colorectal carcinoma cells. Cancer Lett. 2009; 279: $39-46$.

26. Leav I, Plescia J, Goel HL, Li J, Jiang Z, Cohen RJ, Languino LR, Altieri DC. Cytoprotective mitochondrial chaperone TRAP-1 as a novel molecular target in localized and metastatic prostate cancer. Am J Pathol. 2010; 176: 393-401.
27. Kang BH, Plescia J, Dohi T, Rosa J, Doxsey SJ, Altieri DC. Regulation of tumor cell mitochondrial homeostasis by an organelle-specific Hsp90 chaperone network. Cell. 2007; 131: 257-270.

28. Matassa DS, Amoroso MR, Lu H, Avolio R, Arzeni D, Procaccini C, Faicchia D, Maddalena F, Simeon V, Agliarulo I, Zanini E, Mazzoccoli C, Recchi C, et al. Oxidative metabolism drives inflammation-induced platinum resistance in human ovarian cancer. Cell Death Differ. 2016; 23: 1542-1554.

29. Zhang B, Wang J, Huang Z, Wei P, Liu Y, Hao JF, Zhao LJ, Zhang FL, Tu YP, Wei TT. Aberrantly upregulated TRAP1 is required for tumorigenesis of breast cancer. Oncotarget. 2015; 6: 44495-44508. doi: 10.18632/oncotarget.6252.

30. Sharpless NE, Depinho RA. The mighty mouse: genetically engineered mouse models in cancer drug development. Nat Rev Drug Discov. 2006; 5: 741-754.

31. Gopinathan A, Tuveson DA. The use of GEM models for experimental cancer therapeutics. Dis Model Mech. 2008; 1: 83-86.

32. Guy CT, Cardiff RD, Muller WJ. Induction of mammary tumors by expression of polyomavirus middle $\mathrm{T}$ oncogene: a transgenic mouse model for metastatic disease. Mol Cell Biol. 1992; 12: 954-961.

33. Lin EY, Jones JG, Li P, Zhu L, Whitney KD, Muller WJ, Pollard JW. Progression to malignancy in the polyoma middle $\mathrm{T}$ oncoprotein mouse breast cancer model provides a reliable model for human diseases. Am J Pathol. 2003; 163: 2113-2126.

34. Grad I, Cederroth CR, Walicki J, Grey C, Barluenga S, Winssinger N, De Massy B, Nef S, Picard D. The molecular chaperone $\mathrm{Hsp} 9 \alpha$ is required for meiotic progression of spermatocytes beyond pachytene in the mouse. PLoS ONE. 2010; 5: e15770.

35. Lisanti S, Tavecchio M, Chae YC, Liu Q, Brice AK, Thakur ML, Languino LR, Altieri DC. Deletion of the mitochondrial chaperone TRAP-1 uncovers global reprogramming of metabolic networks. Cell Rep. 2014; 8: 671-677.

36. Mühlebach G. Functional characterization of the mitochondrial Hsp90 family member TRAP1. Doctoral thesis, University of Geneva. 2012.

37. Fantozzi A, Christofori G. Mouse models of breast cancer metastasis. Breast Cancer Res. 2006; 8: 212.

38. McCready J, Wong DS, Burlison JA, Ying W, Jay DG. An impermeant ganetespib analog inhibits extracellular Hsp90mediated cancer cell migration that involves lysyl oxidase 2-like protein. Cancers. 2014; 6: 1031-1046.

39. Ringner M, Fredlund E, Hakkinen J, Borg A, Staaf J. GOBO: gene expression-based outcome for breast cancer online. PLoS ONE. 2011; 6: e17911.

40. van der Weyden L, Arends MJ, Campbell AD, Bald T, Wardle-Jones H, Griggs N, Velasco-Herrera MD, Tuting T, Sansom OJ, Karp NA, Clare S, Gleeson D, Ryder E, et al. 
Genome-wide in vivo screen identifies novel host regulators of metastatic colonization. Nature. 2017; 541: 233-236.

41. Azoitei N, Diepold K, Brunner C, Rouhi A, Genze F, Becher A, Kestler H, van Lint J, Chiosis G, Koren J, 3rd, Frohling S, Scholl C, Seufferlein T. HSP90 supports tumor growth and angiogenesis through PRKD2 protein stabilization. Cancer Res. 2014; 74: 7125-7136.

42. Lu C, Liu D, Jin J, Deokar H, Zhang Y, Buolamwini JK, $\mathrm{Yu}$ X, Yan C, Chen X. Inhibition of gastric tumor growth by a novel Hsp90 inhibitor. Biochem Pharmacol. 2013; 85: 1246-1256.

43. Williams CR, Tabios R, Linehan WM, Neckers L. Intratumor injection of the Hsp90 inhibitor 17AAG decreases tumor growth and induces apoptosis in a prostate cancer xenograft model. J Urol. 2007; 178: 1528-1532.

44. Price JT, Quinn JM, Sims NA, Vieusseux J, Waldeck K, Docherty SE, Myers D, Nakamura A, Waltham MC, Gillespie MT, Thompson EW. The heat shock protein 90 inhibitor, 17-allylamino-17-demethoxygeldanamycin, enhances osteoclast formation and potentiates bone metastasis of a human breast cancer cell line. Cancer Res. 2005; 65: 4929-4938.

45. Neckers L, Workman P. Hsp90 molecular chaperone inhibitors: are we there yet? Clin Cancer Res. 2012; 18: 64-76.

46. Trepel J, Mollapour M, Giaccone G, Neckers L. Targeting the dynamic HSP90 complex in cancer. Nat Rev Cancer. 2010; 10: 537-549.

47. Kang BH, Tavecchio M, Goel HL, Hsieh CC, Garlick DS, Raskett CM, Lian JB, Stein GS, Languino LR, Altieri DC. Targeted inhibition of mitochondrial Hsp90 suppresses localised and metastatic prostate cancer growth in a genetic mouse model of disease. Br J Cancer. 2011; 104: 629-634.

48. Kang BH, Siegelin MD, Plescia J, Raskett CM, Garlick DS, Dohi T, Lian JB, Stein GS, Languino LR, Altieri DC. Preclinical characterization of mitochondria-targeted small molecule hsp90 inhibitors, gamitrinibs, in advanced prostate cancer. Clin Cancer Res. 2010; 16: 4779-4788.

49. Lisanti S, Garlick DS, Bryant KG, Tavecchio M, Mills GB, Lu Y, Kossenkov AV, Showe LC, Languino LR, Altieri DC. transgenic expression of the mitochondrial chaperone TNFR-associated protein 1 (TRAP1) accelerates prostate cancer development. J Biol Chem. 2016; 291: 25247-25254.

50. Sciacovelli M, Guzzo G, Morello V, Frezza C, Zheng L, Nannini N, Calabrese F, Laudiero G, Esposito F, Landriscina M, Defilippi P, Bernardi P, Rasola A. The mitochondrial chaperone TRAP1 promotes neoplastic growth by inhibiting succinate dehydrogenase. Cell Metab. 2013; 17: 988-999.

51. Tian X, Ma P, Sui CG, Meng FD, Li Y, Fu LY, Jiang T, Wang Y, Jiang YH. Suppression of tumor necrosis factor receptor-associated protein 1 expression induces inhibition of cell proliferation and tumor growth in human esophageal cancer cells. FEBS J. 2014; 281: 2805-2819.

52. McCready J, Sims JD, Chan D, Jay DG. Secretion of extracellular hsp90 $\alpha$ via exosomes increases cancer cell motility: a role for plasminogen activation. BMC Cancer. 2010; 10: 294.

53. Nagaraju GP, Long TE, Park W, Landry JC, TaliaferroSmith L, Farris AB, Diaz R, El-Rayes BF. Heat shock protein 90 promotes epithelial to mesenchymal transition, invasion, and migration in colorectal cancer. Mol Carcinog. 2015; 54: 1147-1158.

54. Taiyab A, Rao Ch M. HSP90 modulates actin dynamics: inhibition of HSP90 leads to decreased cell motility and impairs invasion. Biochim Biophys Acta. 2011; 1813: 213221.

55. Sidera K, Gaitanou M, Stellas D, Matsas R, Patsavoudi E. A critical role for HSP90 in cancer cell invasion involves interaction with the extracellular domain of HER-2. J Biol Chem. 2008; 283: 2031-2041.

56. El Hamidieh A, Grammatikakis N, Patsavoudi E. Cell surface Cdc37 participates in extracellular HSP90 mediated cancer cell invasion. PLoS ONE. 2012; 7: e42722.

57. Gopal U, Bohonowych JE, Lema-Tome C, Liu A, GarrettMayer E, Wang B, Isaacs JS. A novel extracellular Hsp90 mediated co-receptor function for LRP1 regulates EphA2 dependent glioblastoma cell invasion. PLoS ONE. 2011; 6: e17649.

58. Schmitt E, Gehrmann M, Brunet M, Multhoff G, Garrido C. Intracellular and extracellular functions of heat shock proteins: repercussions in cancer therapy. J Leukoc Biol. 2007; 81: 15-27.

59. Tsutsumi S, Neckers L. Extracellular heat shock protein 90: a role for a molecular chaperone in cell motility and cancer metastasis. Cancer Sci. 2007; 98: 1536-1539.

60. Ou Y, Liu L, Xue L, Zhou W, Zhao Z, Xu B, Song Y, Zhan Q. TRAP1 shows clinical significance and promotes cellular migration and invasion through STAT3/MMP2 pathway in human esophageal squamous cell cancer. J Genet Genomics. 2014; 41: 529-537.

61. Gallegos Ruiz MI, Floor K, Roepman P, Rodriguez JA, Meijer GA, Mooi WJ, Jassem E, Niklinski J, Muley T, van Zandwijk N, Smit EF, Beebe K, Neckers L, et al. Integration of gene dosage and gene expression in nonsmall cell lung cancer, identification of HSP90 as potential target. PLoS ONE. 2008; 3: e0001722.

62. Flandrin P, Guyotat D, Duval A, Cornillon J, Tavernier E, Nadal N, Campos L. Significance of heat-shock protein (HSP) 90 expression in acute myeloid leukemia cells. Cell Stress Chaperones. 2008; 13: 357-364.

63. Wang J, Cui S, Zhang X, Wu Y, Tang H. High expression of heat shock protein 90 is associated with tumor aggressiveness and poor prognosis in patients with advanced gastric cancer. PLoS ONE. 2013; 8: e62876.

64. Lo PK, Kanojia D, Liu X, Singh UP, Berger FG, Wang Q, Chen H. CD49f and CD61 identify Her2/neu-induced mammary tumor-initiating cells that are potentially derived from luminal progenitors and maintained by the integrinTGF $\beta$ signaling. Oncogene. 2012; 31: 2614-2626. 